\title{
Cognitive behavioural therapy with optional graded exercise therapy in patients with severe fatigue with myotonic dystrophy type 1: a multicentre, single-blind, randomised trial
}

Citation for published version (APA):

Okkersen, K., Jimenez-Moreno, C., Wenninger, S., Daidj, F., Glennon, J., Cumming, S., Littleford, R., Monckton, D. G., Lochmuller, H., Catt, M., Faber, C. G., Hapca, A., Donnan, P. T., Gorman, G., Bassez, G., Schoser, B., Knoop, H., Treweek, S., van Engelen, B. G. M., \& OPTIMISTIC Consortium (2018). Cognitive behavioural therapy with optional graded exercise therapy in patients with severe fatigue with myotonic dystrophy type 1: a multicentre, single-blind, randomised trial. Lancet Neurology, 17(8), 671-680. https://doi.org/10.1016/S1474-4422(18)30203-5

Document status and date:

Published: 01/08/2018

DOI:

10.1016/S1474-4422(18)30203-5

Document Version:

Publisher's PDF, also known as Version of record

Document license:

Taverne

Please check the document version of this publication:

- A submitted manuscript is the version of the article upon submission and before peer-review. There can be important differences between the submitted version and the official published version of record. People interested in the research are advised to contact the author for the final version of the publication, or visit the DOI to the publisher's website.

- The final author version and the galley proof are versions of the publication after peer review.

- The final published version features the final layout of the paper including the volume, issue and page numbers.

Link to publication

\footnotetext{
General rights rights.

- You may freely distribute the URL identifying the publication in the public portal. please follow below link for the End User Agreement:

www.umlib.nl/taverne-license

Take down policy

If you believe that this document breaches copyright please contact us at:

repository@maastrichtuniversity.nl

providing details and we will investigate your claim.
}

Copyright and moral rights for the publications made accessible in the public portal are retained by the authors and/or other copyright owners and it is a condition of accessing publications that users recognise and abide by the legal requirements associated with these

- Users may download and print one copy of any publication from the public portal for the purpose of private study or research.

- You may not further distribute the material or use it for any profit-making activity or commercial gain

If the publication is distributed under the terms of Article 25fa of the Dutch Copyright Act, indicated by the "Taverne" license above, 


\title{
Cognitive behavioural therapy with optional graded exercise therapy in patients with severe fatigue with myotonic dystrophy type 1: a multicentre, single-blind, randomised trial
}

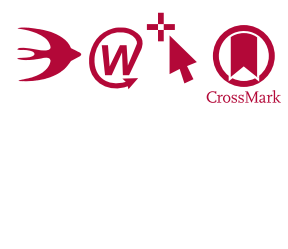

\author{
Kees Okkersen*, Cecilia Jimenez-Moreno*, Stephan Wenninger*, Ferroudja Daidj*, Jeffrey Glennon, Sarah Cumming, Roberta Littleford, \\ Darren G Monckton, Hanns Lochmüller, Michael Catt, Catharina G Faber, Adrian Hapca, Peter T Donnan, Gráinne Gorman*, Guillaume Bassez*, \\ Benedikt Schoser*, Hans Knoop*, Shaun Treweek*, Baziel G M van Engelen*, for the OPTIMISTIC consortium†
}

\begin{abstract}
Summary
Background Myotonic dystrophy type 1 is the most common form of muscular dystrophy in adults and leads to severe fatigue, substantial physical functional impairment, and restricted social participation. In this study, we aimed to determine whether cognitive behavioural therapy optionally combined with graded exercise compared with standard care alone improved the health status of patients with myotonic dystrophy type 1.
\end{abstract}

Methods We did a multicentre, single-blind, randomised trial, at four neuromuscular referral centres with experience in treating patients with myotonic dystrophy type 1 located in Paris (France), Munich (Germany), Nijmegen (Netherlands), and Newcastle (UK). Eligible participants were patients aged 18 years and older with a confirmed genetic diagnosis of myotonic dystrophy type 1 , who were severely fatigued (ie, a score of $\geq 35$ on the checklistindividual strength, subscale fatigue). We randomly assigned participants (1:1) to either cognitive behavioural therapy plus standard care and optional graded exercise or standard care alone. Randomisation was done via a central webbased system, stratified by study site. Cognitive behavioural therapy focused on addressing reduced patient initiative, increasing physical activity, optimising social interaction, regulating sleep-wake patterns, coping with pain, and addressing beliefs about fatigue and myotonic dystrophy type 1 . Cognitive behavioural therapy was delivered over a 10-month period in 10-14 sessions. A graded exercise module could be added to cognitive behavioural therapy in Nijmegen and Newcastle. The primary outcome was the 10-month change from baseline in scores on the DM1-Activ-c scale, a measure of capacity for activity and social participation (score range 0-100). Statistical analysis of the primary outcome included all participants for whom data were available, using mixed-effects linear regression models with baseline scores as a covariate. Safety data were presented as descriptives. This trial is registered with ClinicalTrials gov, number NCT02118779.

Findings Between April 2, 2014, and May 29, 2015, we randomly assigned 255 patients to treatment: 128 to cognitive behavioural therapy plus standard care and 127 to standard care alone. 33 (26\%) of 128 assigned to cognitive behavioural therapy also received the graded exercise module. Follow-up continued until Oct 17, 2016. The DM1Activ-c score increased from a mean (SD) of $61.22(17.35)$ points at baseline to $63.92(17.41)$ at month 10 in the cognitive behavioural therapy group (adjusted mean difference $1 \cdot 53,95 \% \mathrm{CI}-0 \cdot 14$ to $3 \cdot 20$ ), and decreased from $63.00(17.35)$ to $60.79(18.49)$ in the standard care group $(-2.02,-4.02$ to -0.01$)$, with a mean difference between groups of 3.27 points (95\% CI 0.93 to $5.62, \mathrm{p}=0.007)$. 244 adverse events occurred in $65(51 \%)$ patients in the cognitive behavioural therapy group and 155 in $63(50 \%)$ patients in the standard care alone group, the most common of which were falls (155 events in 40 [31\%] patients in the cognitive behavioural therapy group and 71 in 33 [26\%] patients in the standard care alone group). 24 serious adverse events were recorded in 19 (15\%) patients in the cognitive behavioural therapy group and 23 in 15 (12\%) patients in the standard care alone group, the most common of which were gastrointestinal and cardiac.

Interpretation Cognitive behavioural therapy increased the capacity for activity and social participation in patients with myotonic dystrophy type 1 at 10 months. With no curative treatment and few symptomatic treatments, cognitive behavioural therapy could be considered for use in severely fatigued patients with myotonic dystrophy type 1 .

Funding The European Union Seventh Framework Programme.

Copyright (C) 2018 Elsevier Ltd. All rights reserved.

\section{Introduction}

Myotonic dystrophy type 1 is an autosomal dominant, chronic, progressive, multisystem disorder, and the most common form of muscular dystrophy in adults. ${ }^{1}$ The disease leads to substantial physical impairment, which, in combination with the neuropsychological effects of the condition, results in severely restricted social participation..$^{2-6}$ No curative treatment exists, and there is
Lancet Neurol 2018; 17: 671-80 Published Online June 19, 2018 http://dx.doi.org/10.1016 S1474-4422(18)30203-5 See Comment page 652

${ }^{*}$ Contributed equally

†Names listed in the appendix

Department of Neurology, Donders Institute for Brain Cognition and Behaviour, Radboud University Medical Centre, Nijmegen, Netherlands (K Okkersen MD,

Prof B G M van Engelen MD); Institute of Genetic Medicine (C)imenez-Moreno PhD, Prof H Lochmüller MD), Institute of Neuroscience (G Gorman MD), National Innovation Centre for Ageing (Prof M Catt PhD), University of Newcastle, Newcastle, UK; Friedrich-Baur-Institute, Department of Neurology, Klinikum der Universität München, LudwigMaximilians-Universität München, Munich, Germany (SWenninger MD, Prof B Schoser MD); Neuromuscular Reference Centre, Pitié-Salpêtrière Hospital, Assistance PubliqueHôpitaux de Paris, Paris, France (F Daidj, Prof G Bassez MD); Department of Cognitive Neuroscience, Donders Institute for Brain Cognition and Behaviour, Radboud University Medical Centre, Nijmegen, Netherlands (J Glennon PhD); Institute of Molecular, Cell and Systems Biology, College of Medical, Veterinary and Life Sciences, University of Glasgow, Glasgow, UK (S Cumming PhD, Prof D G Monckton PhD); Tayside Clinical Trials Unit, University of Dundee, Dundee, UK (R Littleford PhD, A Hapca PhD, Prof PT Donnan PhD); Department of Neurology, 


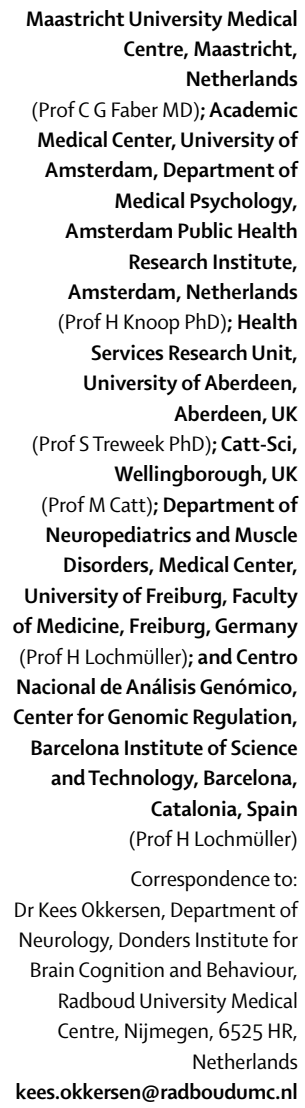

Research in context

\section{Evidence before this study}

There is no cure for myotonic dystrophy type 1 and symptomatic treatment options are limited in this multisystem disease. We searched PubMed for original research and review articles published before March 1, 2018, without language restriction. Keywords were "myotonic dystrophy type 1 " in combination with "therapy", "trial", and "randomised trial". Therapeutic trials were few and included small numbers of patients. Smaller studies provided some evidence for a benefit from physical exercise therapy. Health status in myotonic dystrophy type 1 is determined by several factors, some of which might be amenable to treatment, such as fatigue, reduced initiative, and physical inactivity. For chronic neuromuscular diseases in general, there is accumulating evidence for prescribing an active lifestyle and low-to-moderate intensity aerobic exercise training. However, there is a need for high-quality, disease-specific, randomised trials investigating the effect of behavioural change interventions on health status.

\section{Added value of this study}

We used a novel trial approach (a randomised, controlled study of cognitive behavioural therapy in a genetic disease) based on a previously reported model based on a previously reported model built specifically for myotonic dystrophy type 1 . Our findings showed that in severely fatigued adult patients with myotonic dystrophy type 1 , addition of an individually-tailored, 10-month cognitive behavioural therapy programme optionally combined with graded exercise led to increases in objective physical activity and exercise capacity, decreased fatigue, and improved activity and participation as measured by the DM1-Activ-c score, but without evidence of improved self-reported quality of life. Although cognitive behavioural therapy was generally safe, the frequency of reported falls was increased.

\section{Implications of all the available evidence}

Smaller studies of physical exercise in patients with myotonic dystrophy type 1 have shown its feasibility and benefit on patients' health status. The findings from our study add to the existing evidence by confirming, in a large multicentre cohort, the feasibility of behavioural change intervention and its efficacy through improvements in capacity for activity and participation, fatigue, and exercise capacity. Cognitive behavioural therapy could be implemented into existing rehabilitation programmes for myotonic dystrophy type 1 , if combined with appropriate measures to prevent falls. little evidence for the efficacy of rehabilitative approaches, resulting in an unmet need for treatments that aim to improve health status.?

A myotonic dystrophy type 1-specific model of factors determining health status was empirically derived from the findings of our previous longitudinal study. ${ }^{8}$ This model predicts that patient-reported health status can be improved by addressing reduced patient initiative, optimising physical activity, and alleviating fatigue. Previous studies have shown that fatigue is a highly prevalent and debilitating symptom of myotonic dystrophy type $1 .^{9,10}$ In other conditions such as chronic fatigue syndrome and type 1 diabetes, cognitive behavioural therapy has been effective in relieving fatigue. ${ }^{11,12}$ In facioscapulohumeral muscular dystrophy, cognitive behavioural therapy reduced fatigue and increased objective activity (measured with actometry) and social participation. ${ }^{13}$ Additionally, accumulating evidence supports the beneficial effects of low-to-moderate-intensity strength and aerobic exercise training, and of an active lifestyle, in neuromuscular diseases..$^{14,15}$ Nevertheless, previous reviews have concluded that studies assessing graded activity in neuromuscular diseases are limited in number and quality, and that there is a need for disease-specific, randomised, controlled trials investigating the effect of activity on health status..$^{14,16}$ We therefore did a large randomised trial to determine whether cognitive behavioural therapy plus optional graded exercise improved the health status of patients with myotonic dystrophy type 1 compared with standard care alone. ${ }^{17}$

\section{Methods}

\section{Study design and participants}

We did a multicentre, randomised, single-blind trial, at four neuromuscular referral centres with experience in treating patients with myotonic dystrophy type 1 located in Paris (France), Munich (Germany), Nijmegen (Netherlands), and Newcastle (UK). The study was approved by the institutional review boards at each of the four clinical sites. The study protocol has previously been published. ${ }^{17}$

We recruited patients with a confirmed genetic diagnosis of myotonic dystrophy type 1 aged 18 years and older who were severely fatigued (as measured by the checklist-individual strength subscale fatigue [CIS-fatigue], score $\geq 35$ ), ${ }^{18}$ able to walk independently (walking aids permitted), and able to undergo trial interventions. The main exclusion criteria were neurological or orthopaedic comorbidity interfering with the interventions or possibly influencing outcomes. The full list of exclusion criteria can be found in the appendix. Patients were recruited by invitation via myotonic dystrophy type 1 registries, from clinics via their treating neurologists, or independently through study awareness by patient organisations. We invited the patients' caregivers to participate, as described previously. ${ }^{17}$ Patients gave written informed consent before study entry. 


\section{Randomisation and masking}

We randomly assigned participants (1:1) either to cognitive behavioural therapy plus standard care and optional graded exercise or to standard care alone. Randomisation was done via the central Tayside Randomisation webbased system (TRuST) developed by the Tayside Clinical Trials Unit (University of Dundee, Dundee, UK). Trials unit statisticians and data management staff programmed TRuST to implement the randomisation described in the OPTIMISTIC protocol so that randomisation was stratified by site (location of inclusion) and minimised for baseline severity of myotonic dystrophy type 1 (as assessed by the muscular impairment rating scale [MIRS]) and for baseline involvement of a caregiver. ${ }^{19}$ Immediate family members (ie, parents, children, and siblings) were allocated as a cluster to avoid treatment contamination. Only outcome adjudicators were masked to treatment allocation; they were also instructed to refrain from interactions with the patient that could disclose treatment allocation. During therapy, patients were discouraged from disclosing their treatment allocation to outcome adjudicators.

\section{Procedures}

Patients in the comparison group received standard care applicable to each individual's country (appendix). In addition to receiving standard care, all patients randomised to the intervention group also received cognitive behavioural therapy (details in the appendix). ${ }^{17}$ In a process of shared decision making on the basis of therapists' assessment and questionnaire assessment, cognitive behavioural therapy was customised to individual participants by the selection of one or more appropriate treatment modules: regulating sleep-wake pattern, compensating for reduced patient initiative, formulating helpful beliefs about fatigue and myotonic dystrophy type 1 , optimising social interactions, and coping with pain. To ensure a high degree of treatment integrity, cognitive behavioural therapy was manual based, delivered by therapists experienced in cognitive behavioural therapy with extensive training before the start of the trial, and monitored during the delivery of the intervention (appendix). The treatment manual is available upon request from HK (hans.knoop@amc.uva. nl). We assessed treatment integrity of cognitive behavioural therapy given during the trial through therapist-recorded case report forms from each session from every cognitive behavioural therapy participant, and by the assessment of audio records of cognitive behavioural therapy sessions that were made during the intervention (appendix).

If considered appropriate through a process of shared decision making between cognitive behavioural therapist and participant, a graded exercise module supervised by a physical therapist could optionally be added to cognitive behavioural therapy (appendix). Although we planned this addition in all four centres, differences in standard care meant we could implement graded exercise at only two of four sites (Nijmegen and Newcastle). As it was not possible to offer the graded exercise module as an option within the French and German care pathways, this constituted a protocol deviation (appendix). The graded exercise module constituted a structured exercise programme aimed at increasing physical fitness. The programme was individually tailored, but targeted incorporating moderate-intensity exercises (eg, walking, cycling, jogging, or dancing) for at least half an hour, three times per week. The graded exercise module was given during the intervention period.

The overall intervention (cognitive behavioural therapy and graded exercise when applicable) was scheduled for a duration of 10 months, starting directly after randomisation. Patients were to receive 10-14 sessions of cognitive behavioural therapy (no specific duration specified), with most sessions delivered in the first 4-5 months. There were up to five assessment visits: eligibility screening followed by baseline, 5, 10, and 16 months post-randomisation, with the primary outcome measured at 10 months. We planned for a minimum of five face-to-face sessions, but other communication formats, such as telephone or video calls were acceptable. Onsite and remote visits to assess protocol compliance and adherence to good clinical practice guidelines were done during the study by local trial staff and by staff from the Tayside Clinical Trials Unit.

\section{Outcomes}

The primary outcome was the change from baseline in scores on the DM1-Activ-c scale at the end of the 10-month intervention period (see appendix for details on all outcome measures). This disease-specific, Raschbuilt scale is a patient-reported outcome measure of capacity for activity and social participation with a 0-100 interval range (a higher score indicates higher capacity)..$^{20,21}$ This scale is the updated version of the previous myotonic dystrophy type 1-Activ scale that had a $0-40$ score range. We based our power calculation on the DM1-Activ scale and planned it to be the primary outcome measure. However, deviating from the study protocol (appendix), we decided to use the DM1-Activ-c scale after criticism of the previous version (published in 2010) led to its revision; the updated version was published in 2015 but was available to us in advance, before the start of the study in 2014. ${ }^{21}$

We had predefined secondary outcome measures categorised into five groups: physical activity and exercise capacity (6-min walk test with Borg scale assessment, myotonic dystrophy health index, and physical activity measured with an accelerometer [appendix]); fatigue and sleepiness (fatigue and daytime sleepiness scale and CIS-fatigue); quality of life (individualised neuromuscular quality of life questionnaire [INQOL]); depressive symptoms (Beck depression inventory-fast screen); and 


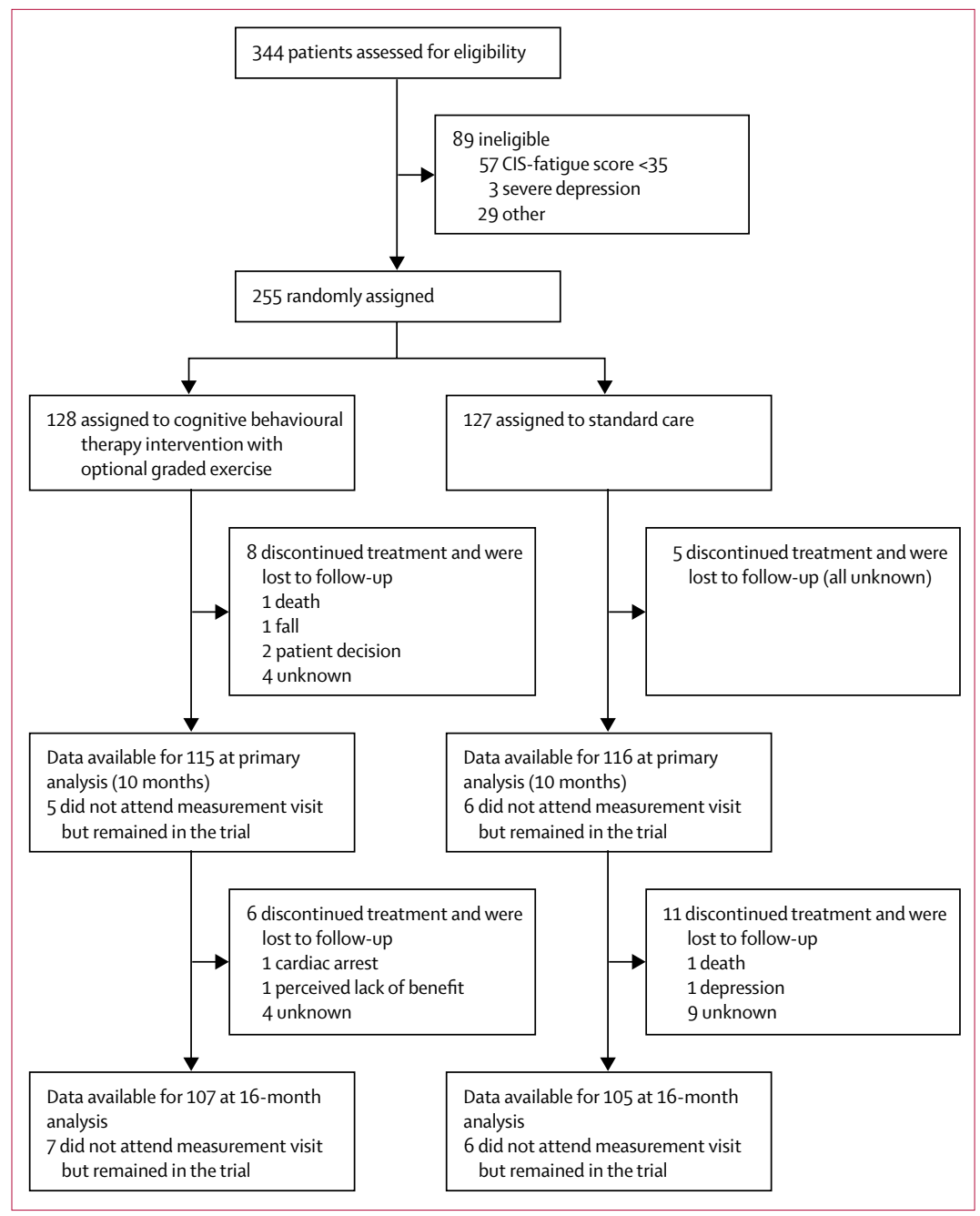

Figure: Trial profile

CIS-fatigue=checklist-individual strength, subscale fatigue.

For statistical analysis plan see http://www.optimistic-dm.eu/ images/com_projectfork/ progress/OPTIMISTIC_SAP.pdf cognition (the apathy evaluation scale-clinician version and Stroop colour-word interference test score; appendix and study protocol). ${ }^{17}$ The Borg scale is a subjective measure of perceived exertion taken immediately after the 6-min walk test; we used the 0-10 scale, as recommended previously. ${ }^{22}$ For accelerometry, we calculated mean $24 \mathrm{~h}$ activity levels, and levels of activity during the five most active and five least active hours of the day. Adverse events and serious adverse events were reported continuously during the study and reviewed at each study visit. ${ }^{17}$

\section{Statistical analysis}

On the basis of a minimum clinically important mean difference of 1.4 on the original 40-item myotonic dystrophy type 1-Activ scale, an SD of $3 \cdot 5$, effect size of $0 \cdot 4$, and $80 \%$ power at the $5 \%$ significance level, a total sample size of 200 patients was required. ${ }^{17} \mathrm{We}$ accounted for the potential of clustering of family members in identical treatment groups by increasing the sample size to 208 . The trial was also fully powered for the 6-min walk test, a secondary outcome assessing exercise capacity. ${ }^{23}$ The recruitment target was set at 296 to allow for a potential dropout rate of up to $30 \%$ based on previous pilot studies in patients with myotonic dystrophy type $1{ }^{24}$ Full details of the sample size calculations have been described previously (see full trial protocol and the statistical analysis plan [SAP]). ${ }^{17}$ The SAP was publicly available before completion of the study. Analyses were done by the trial statistician (AH) and checked by a second statistician (PTD).

The primary outcome analysis was done according to a modified intention-to-treat priciple, including all participants for whom data were available. We used mixed-effects regression models with baseline scores as a covariate to assess the change in the DM1-Activ-c score at 10 months. Previously, raw sum scores of the DM1-Activ-c scale were translated into a log-odds units (logit) scale, using the Rasch model. ${ }^{25}$ Because logits are difficult to interpret intuitively, they were converted into a centile metric score with values ranging from 0 (most severe activity and social participation limitations) to 100 (no activity and social participation limitations). The mixed-effects models included the intervention as a binary variable, age and the minimisation variables (MIRS score and involvement of the caregiver at baseline) as fixed effects, and site as a random effect. Random effects were included for each participant in the repeatedmeasures analyses, as well as for correlation within family groups. Results are presented as model-derived means and 95\% CIs. Planned subgroup analyses were carried out by testing for a subgroup by intervention interaction, as detailed previously (SAP). ${ }^{17}$ Predefined subgroups were implemented for the number of cognitive behavioural therapy sessions attended, clinical site, severity of myotonic dystrophy type 1 as defined by MIRS score, involvement of the caregiver, age, sex, and addition of the graded exercise module to cognitive behavioural therapy. All these analyses were repeated for all secondary outcome measures. Additionally, we did post-hoc repeated measures analysis for primary and secondary outcomes at all timepoints $(5$ months, 10 months, and 16 months). We used SAS software (version 9.4) for statistical analyses. An independent advisory committee oversaw the study. This trial is registered with ClinicalTrials.gov, number NCT02118779.

\section{Role of the funding source}

The funder of the study had no role in study design, data collection, data analysis, data interpretation, or writing of the report. All authors had full access to all the data in the study and had final responsibility for the decision to submit for publication. Researchers wishing to access the data collected in the OPTIMISTIC study are requested to contact BGMvE (baziel.vanengelen@ radboudumc.nl) and sign a data access agreement. Requests for access will be reviewed by a panel involving 
one representative from each of the four clinical sites, chaired by BGMvE.

\section{Results}

Between April 2, 2014, and May 29, 2015, we randomly assigned 255 patients to treatment: 128 patients to the cognitive behavioural therapy intervention and 127 to standard care alone (figure). Follow-up continued until Oct 17, 2016, when the last patient underwent the 16-month assessment. Baseline characteristics were similar between groups (table 1). 33 (26\%) of the 128 patients assigned to intervention received the additional graded exercise module. There was no crossover from standard care to intervention; four patients assigned to cognitive behavioural therapy considered it too much burden and did not attend any sessions, but remained in the trial. At 10 months, 231 (91\%) patients completed the primary outcome evaluation, with similar losses to followup across both groups. The reasons given for trial withdrawal included the burden of travelling to the clinical site for trial measurements and the number of questionnaires to be completed at each visit.

During the study, some protocol violations occurred (appendix). The most important of these was that we made use of the DM1-Activ-c scale. Additionally, although we planned to offer graded exercise in all four centres, we were able to do so only in Nijmegen and Newcastle, thus limiting the availability of this add-on to cognitive behavioural therapy. Other deviations are in the appendix.

After 10 months, there was an adjusted mean increase in scores on the DM1-Activ-c scale of 1.53 points ( $95 \% \mathrm{CI}$ $-0 \cdot 14$ to $3 \cdot 20)$ in the cognitive behavioural therapy group compared with an adjusted mean decrease of -2.02 points $(-4.02$ to $-1 \cdot 01)$ in the standard care group (table 2). In our predefined primary outcome analysis of DM1-Activ-c, there was a difference between groups of $3 \cdot 27$ points $(95 \%$ CI $0 \cdot 93$ to $5 \cdot 62, \mathrm{p}=0 \cdot 007)$ in favour of the intervention group at 10 months. Differences at 10 months in favour of cognitive behavioural therapy were also shown for secondary outcomes of total distance on the 6-min walk test, the fatigue and daytime sleepiness scale, CIS-fatigue, and daily activity levels (mean $24 \mathrm{~h}$ activity and mean activity in the most active $5 \mathrm{~h}$ of the day, over at least 7 consecutive days) measured by accelerometry (table 2). Although scores on the myotonic dystrophy health index and INQOL decreased from baseline to 10-month follow-up in the intervention and standard care group, no significant between-group differences were noted. The secondary outcome measures of apathy evaluation scale, Stroop colour-word interference, accelerometry for the least active $5 \mathrm{~h}$, and Beck depression inventory-fast screen showed no change over time and no between-group differences (table 2).

With one exception (the effect of site on fatigue and daytime sleepiness scale at 10 months), prespecified subgroup analyses yielded no significant interactions of age, sex, site, severity of myotonic dystrophy type 1 as

\begin{tabular}{|c|c|c|}
\hline & $\begin{array}{l}\text { Cognitive behavioural } \\
\text { therapy intervention group } \\
(n=128)\end{array}$ & $\begin{array}{l}\text { Standard care group } \\
(n=127)\end{array}$ \\
\hline Age (years) & $44 \cdot 8(11 \cdot 7)$ & $46 \cdot 4(11 \cdot 3)$ \\
\hline \multicolumn{3}{|l|}{ Sex } \\
\hline Male & $70(55 \%)$ & $67(53 \%)$ \\
\hline Female & $58(45 \%)$ & $60(47 \%)$ \\
\hline $\mathrm{BMI}\left(\mathrm{kg} / \mathrm{m}^{2}\right)$ & $26 \cdot 5(6 \cdot 1)$ & $26 \cdot 2(5 \cdot 3)$ \\
\hline Age at disease onset (years) & $24 \cdot 9(12 \cdot 6)$ & $26 \cdot 2(13 \cdot 3)$ \\
\hline Duration of disease (years) & $19 \cdot 7(9 \cdot 6)$ & $19 \cdot 4(10 \cdot 5)$ \\
\hline Participants with a family member in the study & $12(9 \%)$ & $18(14 \%)$ \\
\hline \multicolumn{3}{|l|}{ Location of enrolment } \\
\hline Paris, France & $37(29 \%)$ & $34(27 \%)$ \\
\hline Munich, Germany & $33(26 \%)$ & $33(26 \%)$ \\
\hline Newcastle, UK & $25(20 \%)$ & $27(21 \%)$ \\
\hline Nijmegen, Netherlands & $33(26 \%)$ & $33(26 \%)$ \\
\hline Years of education & $14 \cdot 0(3 \cdot 5)$ & $14 \cdot 6(4 \cdot 2)$ \\
\hline MIRS & $3(1-5)$ & $3(1-5)$ \\
\hline \multicolumn{3}{|l|}{ Use of walking aids } \\
\hline Walking with aids* & $23(18 \%)$ & $25(20 \%)$ \\
\hline Intermittent use of wheelchair* & $18(14 \%)$ & $20(16 \%)$ \\
\hline CIS-fatigue & $44.9(5 \cdot 9)$ & $44 \cdot 9(6 \cdot 3)$ \\
\hline BDI-FS & $4 \cdot 3(3 \cdot 1)$ & $4 \cdot 0(3 \cdot 2)$ \\
\hline Involvement of caregiver* & $56(44 \%)$ & $50(39 \%)$ \\
\hline Employment & $46(36 \%)$ & $49(39 \%)$ \\
\hline \multicolumn{3}{|l|}{ Presence of cardiac condition } \\
\hline Cardiac condition (not further specified) & $6(5 \%)$ & $2(2 \%)$ \\
\hline Cardiac arrhythmia or conduction defect & $37(30 \%)$ & $41(33 \%)$ \\
\hline Cardiomyopathy & $3(2 \%)$ & $3(2 \%)$ \\
\hline Presence of pacemaker or ICD & $23(18 \%)$ & $21(17 \%)$ \\
\hline Regular use of assistive ventilatory device & $23(18 \%)$ & $16(13 \%)$ \\
\hline \multicolumn{3}{|l|}{ Medication } \\
\hline Psychostimulant drug use (total) & $25(20 \%)$ & $25(20 \%)$ \\
\hline Modafinil & $20(16 \%)$ & $19(15 \%)$ \\
\hline Ritalin & $2(2 \%)$ & $1(1 \%)$ \\
\hline Antidepressants & $3(2 \%)$ & $5(4 \%)$ \\
\hline \multicolumn{3}{|l|}{ Genetics } \\
\hline Estimated progenitor $\mathrm{CTG}$ repeat length & $233 \cdot 0(50 \cdot 0-789 \cdot 0)$ & $211 \cdot 5(61 \cdot 0-726 \cdot 0)$ \\
\hline Modal CTG repeat length & $508.9(276 \cdot 1)$ & $512 \cdot 3(292 \cdot 2)$ \\
\hline \multicolumn{3}{|c|}{$\begin{array}{l}\text { Data are mean }(\mathrm{SD}), \mathrm{n}(\%) \text {, or median (range). BMI=body-mass index. MIRS=muscular impairment rating scale. } \\
\mathrm{CIS} \text {-fatigue=checklist-individual strength, subscale fatigue. BDI-FS=Beck depression inventory fast-screen. } \\
\mathrm{ICD}=\text { =implantable cardioverter-defibrillator. }{ }^{*} \text { One missing value for walking with aids, intermittent wheelchair use, } \\
\text { and involvement of the caregiver. }\end{array}$} \\
\hline
\end{tabular}

defined by MIRS, involvement of caregiver, number of cognitive behavioural therapy sessions, or the addition of the supervised graded exercise module to cognitive behavioural therapy on primary or secondary outcomes at 10 months, after Bonferroni correction for multiple testing (appendix). In a post-hoc analysis, scores on the CIS-fatigue scale at 10 months decreased to less than 35 in 47 (42\%) of 112 patients in the cognitive behavioural therapy group and in 20 (19\%) of 106 patients in the standard care group. 


\begin{tabular}{|c|c|c|c|c|c|c|c|c|}
\hline & \multicolumn{3}{|c|}{ Cognitive behavioural therapy intervention group ( $n=128$ ) } & \multicolumn{3}{|c|}{ Standard care group $(n=127)$} & \multicolumn{2}{|c|}{$\begin{array}{l}\text { Mean }(95 \% \mathrm{Cl}) \text { difference between } \\
\text { groups }\end{array}$} \\
\hline & $\mathrm{N}$ & $\begin{array}{l}\text { Mean (SD) } \\
\text { unadjusted }\end{array}$ & $\begin{array}{l}\text { Mean change }(95 \% \mathrm{Cl}) \\
\text { from baseline adjusted* }\end{array}$ & $\mathrm{N}$ & $\begin{array}{l}\text { Mean (SD) } \\
\text { unadjusted }\end{array}$ & $\begin{array}{l}\text { Mean change }(95 \% \mathrm{Cl}) \\
\text { from baseline adjusted* }\end{array}$ & Adjusted* & $\mathrm{p}$ value \\
\hline \multicolumn{9}{|c|}{ Primary outcome } \\
\hline \multicolumn{9}{|c|}{ DM1-Activ-c score ${ }^{\dagger}$} \\
\hline Baseline & 128 & $61 \cdot 22(17 \cdot 35)$ & & 127 & $63.00(17 \cdot 35)$ & .. & & .. \\
\hline 10 months & 115 & $63.92(17.41)$ & $1.53(-0.14$ to 3.20$)$ & 116 & $60.79(18.49)$ & $-2.02(-4.02$ to -0.01$)$ & $3.27(0.93$ to 5.62$)$ & 0.007 \\
\hline \multicolumn{9}{|c|}{ Secondary outcomes } \\
\hline \multicolumn{9}{|c|}{ Total distance $(\mathrm{m})$ in 6 -min walk test ${ }^{\dagger}$} \\
\hline Baseline & 128 & $389 \cdot 29(123 \cdot 20)$ & & 127 & $400 \cdot 69(119 \cdot 74)$ & .. & & .. \\
\hline 10 months & 111 & $420.65(134.84)$ & 22.61 (10.60 to 34.61$)$ & 99 & $401 \cdot 10(133.49)$ & $-4.39(-14.49$ to 5.72$)$ & 26.5 (11.1 to 41.8$)$ & 0.0009 \\
\hline \multicolumn{9}{|c|}{ End-of-test Borg score $\ddagger$} \\
\hline Baseline & 128 & $4.56(2.28)$ & .. & & $4.58(2.14)$ & .. & .. & .. \\
\hline 10 months & 111 & $4 \cdot 22(2 \cdot 01)$ & $-0.21(-0.59$ to 1.76$)$ & & $4.60(2.05)$ & $0.235(-0.17$ to 1.79$)$ & $-0.42(-0.89$ to 0.06$)$ & 0.083 \\
\hline \multicolumn{9}{|l|}{ MDHI score $\ddagger$} \\
\hline Baseline & 128 & $37.49(18.33)$ & .. & 127 & $35.64(16.08)$ & .. & .. & .. \\
\hline 10 months & 112 & $31 \cdot 78(19 \cdot 35)$ & $-5 \cdot 30(-7 \cdot 44$ to $-3 \cdot 15)$ & 106 & $33.05(17 \cdot 72)$ & $-2.07(-4.36$ to 0.22$)$ & $-2 \cdot 35(-5 \cdot 35$ to 0.65$)$ & 0.126 \\
\hline \multicolumn{9}{|c|}{ Mean $(24 \mathrm{~h}$ ) physical activity (accelerometry [ENMO]) $\dagger$} \\
\hline Baseline & 128 & $19.92(9.53)$ & .. & 127 & $21.33(12.72)$ & .. & .. & .. \\
\hline 10 months & 88 & $21.22(9.91)$ & $0.977(-0.292$ to 2.247$)$ & 76 & $19 \cdot 32(8 \cdot 85)$ & $-2.192(-3.831$ to -0.554$)$ & $3.23(1.47$ to 5.00$)$ & 0.0005 \\
\hline \multicolumn{9}{|c|}{ Mean (most active $5 \mathrm{~h}$ ) physical activity (accelerometry [ENMO]) $\dagger$} \\
\hline Baseline & 128 & $48.80(26.19)$ & .. & 127 & $51.01(34.56)$ & .. & .. & .. \\
\hline 10 months & 88 & $53.60(29.93)$ & $3.439(-0.897$ to 7.776$)$ & 76 & $47 \cdot 21(24 \cdot 93)$ & $-3.897(-8.366$ to 0.572$)$ & $8.36(2.62$ to 14.10$)$ & 0.005 \\
\hline \multicolumn{9}{|c|}{ Mean (least active $5 \mathrm{~h}$ ) physical activity (accelerometry [ENMO]) $\dagger$} \\
\hline Baseline & 128 & $3.86(0.79)$ & .. & 127 & $4 \cdot 29(2 \cdot 38)$ & .. & .. & .. \\
\hline 10 months & 88 & $3.88(0.78)$ & $0.038(-0.142$ to 0.217$)$ & 76 & $3.80(0.66)$ & $-0.541(-1.154$ to 0.073$)$ & $0.181(-0.059$ to 0.422$)$ & 0.141 \\
\hline \multicolumn{9}{|l|}{ FDSS scoreł } \\
\hline Baseline & 128 & $45.87(9.72)$ & .. & 126 & $46.52(11.54)$ & .. &.. & .. \\
\hline 10 months & 109 & $38.38(10 \cdot 27)$ & $-7 \cdot 44(-9 \cdot 20$ to $-5 \cdot 68)$ & 104 & $43 \cdot 22(10 \cdot 78)$ & $-3 \cdot 50(-5 \cdot 16$ to $-1 \cdot 84)$ & $-4 \cdot 15(-6 \cdot 30$ to $-2 \cdot 00)$ & 0.0002 \\
\hline \multicolumn{9}{|c|}{ CIS-fatigue score $\ddagger$} \\
\hline Baseline & 128 & $44.89(5.92)$ & .. & 127 & $44.88(6.34)$ & .. & .. & .. \\
\hline 10 months & 113 & $36.27(10 \cdot 91)$ & $-8.38(-10.29$ to -6.46$)$ & 106 & $40.62(8.46)$ & $-4 \cdot 34(-5 \cdot 82$ to $-2 \cdot 85)$ & $-3.93(-1.58$ to -6.28$)$ & 0.001 \\
\hline \multicolumn{9}{|c|}{ INQOL quality of life domain scoreł } \\
\hline Baseline & 128 & $78.14(31.94)$ & .. & 127 & $72.72(34.82)$ & .. & .. & .. \\
\hline 10 months & 113 & $69 \cdot 21(35 \cdot 95)$ & $-8.15(-12.96$ to -3.34$)$ & 105 & $70.26(34.80)$ & $-2.27(-8.00$ to 3.47$)$ & $-4 \cdot 52(-11 \cdot 35$ to $2 \cdot 31)$ & 0.196 \\
\hline \multicolumn{9}{|l|}{ BDI-FS score $\neq$} \\
\hline Baseline & 128 & $4 \cdot 31(3 \cdot 10)$ & & 127 & $4.03(3.15)$ & .. & & \\
\hline 10 months & 110 & $4.06(3.44)$ & $-0.330(-0.91$ to 0.241$)$ & 105 & $3.60(3.14)$ & $-0.277(-0.794$ to 0.240$)$ & $0.064(-0.644$ to 0.772$)$ & 0.859 \\
\hline \multicolumn{9}{|l|}{ AES-c score $\ddagger$} \\
\hline Baseline & 128 & $38.87(9.07)$ & .. & 127 & $37.33(8.65)$ & .. & & \\
\hline 10 months & 109 & $36 \cdot 31(8.47)$ & $0.74(-0.57$ to 2.04$)$ & 103 & $37.24(9.84)$ & $-0.41(-1.73$ to 0.90$)$ & $0.63(-0.98$ to 2.25$)$ & 0.444 \\
\hline \multicolumn{9}{|c|}{ Stroop colour-word interference test score $\$ \rrbracket$} \\
\hline Baseline & 128 & $92.19(72 \cdot 26)$ & .. & 127 & $90.27(51.99)$ & .. & .. & .. \\
\hline 10 months & 115 & $73.95(40.15)$ & $-16.093(-26.815$ to -5.370$)$ & 105 & $77 \cdot 75(51.41)$ & $-9.995(-17.127$ to -2.863$)$ & $-0.035(-0.115$ to 0.045$)$ & 0.389 \\
\hline
\end{tabular}

Post-hoc repeated measures analysis of scores on the DM1-Activ-c scale showed improved scores compared with baseline in the intervention group at 5 months, the highest scores at 10 months, and continuing above baseline values until 16 months, although scores were similar to those in the standard care group at 16 months (appendix). The difference between intervention and standard care groups over all periods was in favour of the 
intervention $(p=0 \cdot 004$ for post-hoc repeated measures analysis). Similar temporal patterns occurred with the 6-min walk test, myotonic dystrophy health index, fatigue and daytime sleepiness scale, CIS-fatigue, accelerometry (mean $24 \mathrm{~h}$ and highest $5 \mathrm{~h}$ of activity) and INQOL (appendix). Of these outcomes, significant betweengroup differences were noted for the 6-min walk test, fatigue and daytime sleepiness scale, CIS-fatigue, and accelerometry. Beck depression inventory-fast screen and apathy evaluation scale-clinician version scores were stable across timepoints and there were no significant between-group differences. Stroop colour-word interference scores improved with time in both groups but there were no between-group differences (appendix).

We recorded 399 adverse events in 128 (50\%) patients (table 3). 226 events (57\%) were related to falls, numerically more in the cognitive behavioural therapy intervention group. Adverse events related to infections and infestations comprised mostly infections of the upper respiratory tract, influenza, and infections in the oral cavity. Apart from events related to the respiratory tract, thorax, and mediastinum, all other adverse events were distributed similarly between groups (table 3 ).

47 serious adverse events occurred in 34 patients (13\%) during the study (table 4). These events occurred with similar frequency in the cognitive behavioural therapy intervention group and the standard care group. The distribution of serious adverse events across both groups was similar, with the exception of events related to falls (numerically more in the intervention group than in the standard care alone group).

\section{Discussion}

Data from this prospective trial of severely fatigued adult patients with myotonic dystrophy type 1 showed that, by month 10, cognitive behavioural therapy increased patients' capacity for activity and participation, compared with standard care alone. Additionally, several secondary outcome measures of fatigue (CIS-fatigue and fatigue and daytime sleepiness scale), exercise capacity (6-min walk test), and objective physical activity as measured with accelerometry were significantly improved with cognitive behavioural therapy compared with standard care alone. However, improvements in outcome measures for quality of life and disease burden were not significantly different between groups at 10 months. It should be noted that the trial was not powered for any of the secondary outcome measures except the 6-min walk test.

The multisystem and progressive nature of myotonic dystrophy type 1 leads to severe physical impairment, restricted social participation, and premature death, yet no US Food and Drug Administration-approved therapies are yet available. ${ }^{3,26-28}$ Fatigue is a highly prevalent and debilitating symptom of myotonic dystrophy type 1 that has been shown to have the greatest negative effect on the lives of patients. ${ }^{10}$ Few, if any, fully validated

\begin{tabular}{|c|c|c|c|}
\hline & $\begin{array}{l}\text { Cognitive behavioural } \\
\text { therapy intervention } \\
\text { group }(n=128)\end{array}$ & $\begin{array}{l}\text { Standard care } \\
\text { group }(n=127)\end{array}$ & All patients $(n=255)$ \\
\hline Blood and lymphatics & 0 & $2(2[2 \%])$ & $2(2[<1 \%])$ \\
\hline Cardiac & $4(4[3 \%])$ & $2(2[2 \%])$ & $6(6[2 \%])$ \\
\hline Ear and labyrinth & 0 & $1(1[<1 \%])$ & $1(1[<1 \%])$ \\
\hline Eye disorders & $1(1[<1 \%])$ & $1(1[<1 \%])$ & $2(2[<1 \%])$ \\
\hline Gastrointestinal & $7(5[4 \%])$ & $3(3[2 \%])$ & $10(8[3 \%])$ \\
\hline General disorders & $6(6[5 \%])$ & $6(6[5 \%])$ & $12(12[5 \%])$ \\
\hline Immune system & 0 & $1(1[<1 \%])$ & $1(1[<1 \%])$ \\
\hline Infections and infestations & $32(24$ [19\%]) & $19(15[12 \%])$ & $51(39[15 \%])$ \\
\hline $\begin{array}{l}\text { Injury, poisoning, and procedural } \\
\text { complications }\end{array}$ & $162(46[36 \%])$ & $81(39[31 \%])$ & $243(85[33 \%])$ \\
\hline Falls & $155(40[31 \%])$ & $71(33[26 \%])$ & $226(73[29 \%])$ \\
\hline Investigations & $1(1[<1 \%])$ & $1(1[<1 \%])$ & $2(2[<1 \%])$ \\
\hline Metabolism and nutrition & $1(1[<1 \%])$ & 0 & $1(1[<1 \%])$ \\
\hline Musculoskeletal and connective tissue & $14(14[11 \%])$ & $12(9[7 \%])$ & $26(23[9 \%])$ \\
\hline Neoplasm & $1(1[<1 \%])$ & 0 & $1(1[<1 \%])$ \\
\hline Nervous system & $7(7[5 \%])$ & $9(8[6 \%])$ & $16(15[6 \%])$ \\
\hline Psychiatric & 0 & $2(2[2 \%])$ & $2(2[<1 \%])$ \\
\hline Reproductive system and breast & $1(1[<1 \%])$ & 0 & $1(1[<1 \%])$ \\
\hline Respiratory thoracic mediastinal & $5(5[4 \%])$ & $12(9[7 \%])$ & $17(14[5 \%])$ \\
\hline Skin subcutaneous & $1(1[<1 \%])$ & 0 & $1(1[<1 \%])$ \\
\hline Vascular disorders & $1(1[<1 \%])$ & $3(3[2 \%])$ & $4(4[2 \%])$ \\
\hline Total number of events & $244(65[51 \%])$ & $155(63[50 \%])$ & $399(128[50 \%])$ \\
\hline \multicolumn{4}{|c|}{$\begin{array}{l}\text { Data are the numbers of adverse events that occurred, followed by the number and percentage of patients in whom } \\
\text { these occurred. Events were classified according to System Organ Class (SOC) adverse event terminology. }{ }^{15} \\
\text { Non-occurring adverse events from the SOC list are not included in the table. The numbers in brackets do not always } \\
\text { sum up to the totals presented because some patients had multiple serious adverse events. }\end{array}$} \\
\hline
\end{tabular}

disease-specific outcome measures exist for this disease, complicating the undertaking of clinical trials in myotonic dystrophy type $1 .^{29}$ The sensitivity to change for myotonic dystrophy type 1-specific outcome measures, including the DM1-Activ-c scale, was unknown during the design phase of the trial. Nonetheless, we selected the best outcome measures available at that time, after careful consideration in our consortium and based on consensus literature in the international myotonic dystrophy type 1 community. ${ }^{30}$ The clinical relevance of a $3 \cdot 27$ point difference on the DM1-Activ-c scale at 10 months was supported by concurrent changes in the secondary outcome measures in favour of the intervention group that measured activity, exercise capacity, and fatigue. In particular, the $26.5 \mathrm{~m}$ difference between groups for the 6-min walk test is beyond the minimal clinically important change in myotonic dystrophy type 1, which was previously defined as a $6 \%$ change in walking distance between assessments. ${ }^{23}$ In the cognitive behavioural therapy group, the increase in walking distance from $389 \mathrm{~m}$ to $421 \mathrm{~m}$ represents an increase of approximately $8 \%$. The outcomes at follow-up showed a tendency towards a decrease of the beneficial effects of cognitive behavioural therapy over time. We suggest that booster 


\begin{tabular}{|c|c|c|c|}
\hline & $\begin{array}{l}\text { Cognitive behavioural } \\
\text { therapy intervention } \\
\text { group }(n=128)\end{array}$ & $\begin{array}{l}\text { Standard care } \\
\text { group }(n=127)\end{array}$ & All patients ( $n=255)$ \\
\hline Total falls & $5(5[4 \%])$ & $1(1[<1 \%])$ & $6(6[2 \%])$ \\
\hline Fall & $1(1[<1 \%])$ & 0 & $1(1[<1 \%])$ \\
\hline Fall with fracture (extremity) & $1(1[<1 \%])$ & 0 & $1(1[<1 \%])$ \\
\hline $\begin{array}{l}\text { Fall with suspected or actual cranial } \\
\text { trauma }\end{array}$ & $3(3[2 \%])$ & $1(1[<1 \%])$ & $4(4[2 \%])$ \\
\hline Total pulmonary and non-cardiac chest & $5(5[4 \%])$ & $5(5[4 \%])$ & $10(10[4 \%])$ \\
\hline Pneumonia & $3(3[2 \%])$ & $3(3[2 \%])$ & $6(6[2 \%])$ \\
\hline Chest infection & $1(1[<1 \%])$ & 0 & $1(1[<1 \%])$ \\
\hline Pulmonary embolism & 0 & $2(2[1 \%])$ & $2(2[<1 \%])$ \\
\hline Pneumothorax & $1(1[<1 \%])$ & 0 & $1(1[<1 \%])$ \\
\hline Total cardiac & $5(4[3 \%])$ & $6(4[3 \%])$ & $11(8[3 \%])$ \\
\hline Myocardial infarction & $1(1[<1 \%])$ & $2(2[1 \%])$ & $3(3[1 \%])$ \\
\hline Cardiac arrest & $1(1[<1 \%])$ & 0 & $1(1[<1 \%])$ \\
\hline Atypical chest complaints & $2(2[1 \%])$ & $1(1[<1 \%])$ & $3(3[1 \%])$ \\
\hline Tachycardia & 0 & $2(1[<1 \%])$ & $2(1[<1 \%])$ \\
\hline Arrhythmia & $1(1[<1 \%])$ & 0 & $1(1[<1 \%])$ \\
\hline Pacemaker installation & 0 & $1(1[<1 \%])$ & $1(1[<1 \%])$ \\
\hline Total gastrointestinal & $6(5[4 \%])$ & $5(3[2 \%])$ & $11(8[3 \%])$ \\
\hline Constipation & 0 & $2(1[<1 \%])$ & $2(1[<1 \%])$ \\
\hline Dysphagia & 0 & $1(1[<1 \%])$ & $1(1[<1 \%])$ \\
\hline Gallstone attack & $1(1[<1 \%])$ & $1(1[<1 \%])$ & $2(2[<1 \%])$ \\
\hline Bile cystitis & $1(1[<1 \%])$ & 0 & $1(1[<1 \%])$ \\
\hline Peptic ulcer & 0 & $1(1[<1 \%])$ & $1(1[<1 \%])$ \\
\hline Volvulus & $1(1[<1 \%])$ & 0 & $1(1[<1 \%])$ \\
\hline Gastrointestinal malignancy (liver) & $1(1[<1 \%])$ & 0 & $1(1[<1 \%])$ \\
\hline Ulcerative colitis & $1(1[<1 \%])$ & 0 & $1(1[<1 \%])$ \\
\hline Abdominal pain-unknown cause & $1(1[<1 \%])$ & 0 & $1(1[<1 \%])$ \\
\hline Total other & $3(3[2 \%])$ & $6(5[4 \%])$ & $9(8[3 \%])$ \\
\hline Extremity fracture not related to falls & $1(1[<1 \%])$ & $1(1[<1 \%])$ & $2(2[<1 \%])$ \\
\hline Urinary tract infection & 0 & $1(1[<1 \%])$ & $1(1[<1 \%])$ \\
\hline Vertigo & 0 & $1(1[<1 \%])$ & $1(1[<1 \%])$ \\
\hline Headache of severe intensity & 0 & $1(1[<1 \%])$ & $1(1[<1 \%])$ \\
\hline Leg pain-unknown cause & 0 & $1(1[<1 \%])$ & $1(1[<1 \%])$ \\
\hline Back pain (lumbago) & $1(1[<1 \%])$ & 0 & $1(1[<1 \%])$ \\
\hline (Epileptic) seizure & $1(1[<1 \%])$ & 0 & $1(1[<1 \%])$ \\
\hline Wound dehiscence & 0 & $1(1[<1 \%])$ & $1(1[<1 \%])$ \\
\hline Total serious adverse events & $24(19[15 \%])$ & $23(15[12 \%])$ & $47(34[13 \%])$ \\
\hline
\end{tabular}

Data are the number of adverse events and serious adverse events occurring up to 14 days after the final visit (16 months after baseline), followed by number and percentage of patients in whom these occurred. The numbers in brackets do not always sum up to the totals presented because some patients had multiple serious adverse events.

Table 4: Serious adverse events clinical site, the addition of a graded exercise module, disease severity as measured by MIRS score at study entry, or involvement of a caregiver. This finding means that despite differences in health-care systems, favourable effects can be achieved in different settings. The absence of additive benefit with addition of the graded exercise module suggests that cognitive behavioural therapy alone is capable of increasing the capacity for activity and exercise in patients with myotonic dystrophy type 1 . However, the group of patients who received the graded exercise module was relatively small, which means care is needed when interpreting this result. Moreover, our results do not preclude a beneficial effect of exercise therapy without cognitive behavioural therapy in patients with myotonic dystrophy type 1 , as suggested previously. ${ }^{32,33}$ Finally, we were surprised to find that the involvement of a caregiver with the study did not affect outcome, as we had expected better outcomes through supportive effects when caregivers were involved with the study.

With regard to the safety of cognitive behavioural therapy, the similar distribution of serious adverse events across groups was reassuring. However, falls were numerically more frequent in the intervention group. Falls are a common complication in the natural history of myotonic dystrophy type 1 , but the increased risk of less serious falls linked to the cognitive behavioural therapy intervention underlines the importance of monitoring and, where possible, addressing this issue in clinical practice and future clinical trials. ${ }^{34,35}$ Furthermore, patients may under-report complications related to myotonic dystrophy type 1 such as falls, as a result of reduced disease awareness. ${ }^{36}$ The excess fall frequency in the cognitive behavioural therapy group might be partly explained by better recall in this group resulting from more frequent contacts with trial staff (ie, cognitive behavioural therapists). Another possible explanation is a true increase in fall frequency as a result of spending more time being active, during which time a higher number of falls might occur. Other factors that we did not assess, such as the occurrence of cataracts, might also have influenced our results. It should be noted that the total number of falls (226) recorded in our study is relatively low in comparison with a Swedish study ${ }^{35}$ that reported more than 200 falls occurring over a 1-year period in 43 patients with myotonic dystrophy type 1 . This difference could be due to differences in fall assessment and the fact that less severely affected patients (as defined by MIRS scores) were excluded from the Swedish study. Nevertheless, it seems reasonable to conclude that increasing activity levels in people with myotonic dystrophy type 1 will lead to more falls, though most are minor. Balancing this potential harm against the potential benefit of increased activity levels needs to be a shared decision between patients, carers, and health professionals. 
Our trial was characterised by high recruitment and low dropout rates, by contrast with findings from a previous study of patients with myotonic dystrophy type $1 .{ }^{24}$ The selection of severely fatigued patients means that our results might be applicable to a large proportion of patients with myotonic dystrophy type 1 , because results from a previous study showed severe fatigue occurred in $74 \%$ of otherwise unselected patients with myotonic dystrophy type 1 , using the same instrument and cutoff score (ie, CIS-fatigue $\geq 35$ ). ${ }^{\text {? }}$

The trial had some limitations, including an absence of information on respiratory muscle involvement, which might have affected fatigue, physical activity, and exercise capacity. Additionally, more frequent contact with trial staff for patients in the intervention group might have led to desirability bias: ie, patients providing more desirable answers on patient-reported outcome measures in comparison with the standard care group. Nevertheless, the significant between-group differences of objective physical activity, as measured with accelerometry, and the 6-min walk test, a measure of exercise capacity, argue against desirability bias as a sole explanation for our favourable results. In common with other studies employing accelerometry, there were missing data. ${ }^{37,38}$ However, the quantity of missing data did not differ significantly between groups, and reasons for non-compliance and device loss or failure were similar to those reported in the literature..$^{37,38}$

\section{Contributors}

BGMvE, JG, HK, and ST conceptualised the study and coordinated funding. Recruitment and data collection were done at four clinical sites by KO (Nijmegen), CJ-M (Newcastle), SW (Munich), and FD (Paris), coordinated by BGMvE (Nijmegen), BS (Munich), GB (Paris), and HL and GG (Newcastle). HK, MC, and BGMvE designed the intervention. BGMvE, BS, GB, HL, GG, CGF, and MC designed the outcome measures. PTD and AH did the pre-trial and post-trial statistical analyses. SC and DGM devised and did the genetic analyses. RL and ST coordinated trial design, randomisation, and data collation. MC contributed to the design and utilisation of triaxial accelerometry, measure selection, data cleaning, analytics, and result interpretation. All authors were actively involved throughout in the design, conduct, implementation, and completion of the study. KO wrote the first draft; all authors reviewed the manuscript for intellectual input, and all authors were involved in revisions.

\section{Declaration of interests}

DGM reports grants from the European Union (EU); personal fees from Vertex, Charles River, and Biogen; and personal fees and other funding from AMO Pharma. MC was originally funded to undertake this work within the EU FP7 grant (project number 305697) as co-investigator via Catt-Sci, of which he is a director. PTD reports grants from GSK, Shire, and Novo Nordisk, and is a member of the New Drugs Committee of the Scottish Medicines Consortium (UK). GB reports grants from AFM-Telethon, personal fees and other funding from Lupin Pharmaceuticals, non-financial support and Scientific Advisory Board and travel fees from the Myotonic Dystrophy Foundation, and Scientific Advisory Board fees from AMO Pharma. HK reports grants from the European Union Seventh Framework Program. BGMvE reports grants from the EU Horizon 2020 research and innovation programme (Murab), the Netherlands Organisation for Scientific Research, the Netherlands Organisation for Health Research and Development, Global FSH, Prinses Beatrix Spierfonds, Stichting Spieren voor Spieren, Association Francaise contre les Myopathies, and the Dutch FSHD Foundation. HL, CGF, AH, KO CJ-M, SW, FD, JG, SC, GG, BS, RL, and ST declare no competing interests.

\section{Acknowledgments}

This study was funded by the European Union Seventh Framework Program, under grant agreement number 305697 (the Observational Prolonged Trial In Myotonic dystrophy type 1 to Improve Quality of Life Standards, a Target Identification Collaboration [OPTIMISTIC] project). We thank Marie Kierkegaard (Karolinska University Hospital, Karolinska Institutet, Department of Physical Therapy, Sweden) and Don MacKenzie (Marigold Foundation, Calgary, AB, Canada) as members of the external advisory board for their continued monitoring and recommendations for improvement of our study. The Health Services Research Unit (University of Aberdeen, Aberdeen, UK) receives core funding from the Chief Scientist Office of the Scottish Government Health Directorates.

We acknowledge the contribution to this study made by the Tayside Clinical Trials Unit, University of Dundee (Dundee, UK).

\section{References}

1 Harper PS. Myotonic dystrophy, 3rd edn. London: WB Saunders, 2001.

2 Laberge L, Mathieu J, Auclair J, Gagnon E, Noreau L, Gagnon C. Clinical, psychosocial, and central correlates of quality of life in myotonic dystrophy type 1 patients. Eur Neurol 2013; 70: 308-15.

3 Kierkegaard M, Harms-Ringdahl K, Holmqvist LW, Tollback A. Functioning and disability in adults with myotonic dystrophy type 1. Disabil Rehabil 2011; 33: 1826-36.

4 Gourdon G, Meola G. Myotonic dystrophies: state of the art of new therapeutic developments for the CNS. Front Cell Neurosci 2017; 11: 101.

5 Sansone V, Gandossini S, Cotelli M, Calabria M, Zanetti O, Meola G. Cognitive impairment in adult myotonic dystrophies: a longitudinal study. Neurol Sci 2007; 28: 9-15.

6 Winblad S, Samuelsson L, Lindberg C, Meola G. Cognition in myotonic dystrophy type 1: a 5-year follow-up study. Eur J Neurol 2016; 23: $1471-76$.

7 Turner C, Hilton-Jones D. Myotonic dystrophy: diagnosis, management and new therapies. Curr Opin Neurol 2014; 27: 599-606.

8 Kalkman JS, Schillings ML, Zwarts MJ, van Engelen BG, Bleijenberg $\mathrm{G}$. The development of a model of fatigue in neuromuscular disorders: a longitudinal study. J Psychosom Res 2007; 62: $571-79$

9 Kalkman JS, Schillings ML, van der Werf SP, et al. Experienced fatigue in facioscapulohumeral dystrophy, myotonic dystrophy, and HMSN-I. J Neurol Neurosurg Psychiatry 2005; 76: $1406-09$.

10 Heatwole C, Bode R, Johnson N, et al. Patient-reported impact of symptoms in myotonic dystrophy type 1 (PRISM-1). Neurology 2012; 79: 348-57.

11 Malouff JM, Thorsteinsson EB, Rooke SE, Bhullar N, Schutte NS. Efficacy of cognitive behavioral therapy for chronic fatigue syndrome: a meta-analysis. Clin Psychol Rev 2008; 28: 736-45.

12 Menting J, Tack CJ, van Bon AC, et al. Web-based cognitive behavioural therapy blended with face-to-face sessions for chronic fatigue in type 1 diabetes: a multicentre randomised controlled trial. Lancet Diabetes Endocrinol 2017; 5: 448-56.

13 Voet N, Bleijenberg G, Hendriks J, et al. Both aerobic exercise and cognitive-behavioral therapy reduce chronic fatigue in FSHD: an RCT. Neurology 2014; 83: 1914-22.

14 Cup EH, Pieterse AJ, Ten Broek-Pastoor JM, et al. Exercise therapy and other types of physical therapy for patients with neuromuscular diseases: a systematic review. Arch Phys Med Rehabil 2007; 88: 1452-64.

15 Favejee MM, van den Berg LE, Kruijshaar ME, et al. Exercise training in adults with Pompe disease: the effects on pain, fatigue, and functioning. Arch Phys Med Rehabil 2015; 96: 817-22.

16 Voet NB, van der Kooi EL, Riphagen, II, Lindeman E, van Engelen BG, Geurts AC. Strength training and aerobic exercise training for muscle disease. Cochrane Database Syst Rev 2013; 7: CD003907

17 van Engelen B. Cognitive behaviour therapy plus aerobic exercise training to increase activity in patients with myotonic dystrophy type 1 (DM1) compared to usual care (OPTIMISTIC): study protocol for randomised controlled trial. Trials 2015; 16: 224

18 Worm-Smeitink M, Gielissen M, Bloot L, et al. The assessment of fatigue: psychometric qualities and norms for the Checklist individual strength. J Psychosom Res 2017; 98: 40-46. 
19 Mathieu J, Boivin H, Meunier D, Gaudreault M, Begin P. Assessment of a disease-specific muscular impairment rating scale in myotonic dystrophy. Neurology 2001; 56: 336-40.

20 Hermans MC, Faber CG, De Baets MH, de Die-Smulders CE Merkies IS. Rasch-built myotonic dystrophy type 1 activity and participation scale (DM1-Activ). Neuromuscul Disord 2010; 20: 310-18

21 Hermans MC, Hoeijmakers JG, Faber CG, Merkies IS. Reconstructing the Rasch-built myotonic dystrophy type 1 activity and participation scale. PLoS One 2015; 10: e0139944.

22 ATS Committee on Proficiency Standards for Clinical Pulmonary Function Laboratories. ATS statement: guidelines for the six-minute walk test. Am J Respir Crit Care Med 2002; 166: 111-17.

23 Kierkegaard M, Tollback A. Reliability and feasibility of the six minute walk test in subjects with myotonic dystrophy. Neuromuscul Disord 2007; 17: 943-49.

24 Orngreen MC, Olsen DB, Vissing J. Aerobic training in patients with myotonic dystrophy type 1 . Annal Neurol 2005; 57: 754-57.

25 Vanhoutte EK, Hermans MC, Faber CG, et al. Rasch-ionale for neurologists. J Peripher Nerv Syst 2015; 20: 260-68.

26 Gagnon C, Mathieu J, Jean S, et al. Predictors of disrupted social participation in myotonic dystrophy type 1 . Arch Phys Med Rehabil 2008; 89: 1246-55.

27 Minis MA, Kalkman JS, Akkermans RP, et al. Employment status of patients with neuromuscular diseases in relation to personal factors, fatigue and health status: a secondary analysis. J Rehabil Med 2010; 42: 60-65.

28 Gagnon C, Noreau L, Moxley RT, et al. Towards an integrative approach to the management of myotonic dystrophy type 1 . J Neurol Neurosurg Psychiatry 2007; 78: 800-06.

29 Symonds T, Randall JA, Campbell P. Review of patient-reported outcome measures for use in myotonic dystrophy type 1 patients. Muscle Nerve 2017; 56: 86-92.
30 Gagnon C, Meola G, Hebert LJ, Laberge L, Leone M, Heatwole C. Report of the second Outcome Measures in Myotonic Dystrophy type 1 (OMMYD-2) international workshop. San Sebastian, Spain, October 16, 2013. Neuromuscul Disord 2015; 25: 603-16.

31 Kennedy JC, Dunlop BW, Craighead LW, Nemeroff CB Mayberg HS, Craighead WE. Follow-up of monotherapy remitters in the PReDICT study: Maintenance treatment outcomes and clinical predictors of recurrence. J Consult Clin Psychol 2018; 86: 189-99.

32 Kierkegaard M, Harms-Ringdahl K, Edstrom L, Widen Holmqvist L Tollback A. Feasibility and effects of a physical exercise programme in adults with myotonic dystrophy type 1 : a randomized controlled pilot study. J Rehabil Med 2011; 43: 695-702.

33 Cudia P, Weis L, Baba A, et al. Effects of functional electrical stimulation lower extremity training in myotonic dystrophy type I: a pilot controlled study. Am J Phys Med Rehabil 2016; 95: 809-17.

34 Wiles CM, Busse ME, Sampson CM, Rogers MT, Fenton-May J, van Deursen R. Falls and stumbles in myotonic dystrophy. J Neurol Neurosurg Psychiatry 2006; 77: 393-96.

35 Hammaren E, Kjellby-Wendt G, Lindberg C. Muscle force, balance and falls in muscular impaired individuals with myotonic dystrophy type 1: a five-year prospective cohort study. Neuromuscul Disord 2015; 25: $141-48$

36 Baldanzi S, Bevilacqua F, Lorio R, et al. Disease awareness in myotonic dystrophy type 1 : an observational cross-sectional study. Orphanet J Rare Dis 2016; 11: 34.

37 Lee IM, Shiroma EJ. Using accelerometers to measure physical activity in large-scale epidemiological studies: issues and challenges. Br J Sports Med 2014; 48: 197-201.

38 Matthews CE, Hagstromer M, Pober DM, Bowles HR. Best practices for using physical activity monitors in population-based research. Med Sci Sports Exerc 2012; 44 (suppl 1): S68-76. 